\title{
Quasistatic Load Sharing Behaviours of Concentric Torque-Split Face Gear Transmission with Flexible Face Gear
}

\author{
Ning Zhao, Wang Li ${ }^{\mathbb{D}}$, Tao Hu, Hui Guo, Ruchuan Zhou, and Yanjun Peng \\ Northwestern Polytechnical University, 127 West Youyi Road, Xi'an, Shaanxi 710072, China \\ Correspondence should be addressed to Wang Li; lw201906@126.com
}

Received 19 August 2018; Accepted 22 October 2018; Published 6 November 2018

Academic Editor: Jaime Gallardo-Alvarado

Copyright (C) 2018 Ning Zhao et al. This is an open access article distributed under the Creative Commons Attribution License, which permits unrestricted use, distribution, and reproduction in any medium, provided the original work is properly cited.

\begin{abstract}
The concentric torque-split face gear transmission is mainly developed for the rotorcraft which demands high power density and large speed reduction ratio. This paper aims at predicting the load sharing behaviours among paths. An original quasistatic load sharing analysis model, which is a hybrid finite element/lumped parameter quasistatic gear model, is presented. The connection between spur gear and face gear is also established. A number of numerical simulations of load sharing behaviour analysis are conducted. The mechanism of uneven load sharing is revealed. It is observed that the support stiffness of pinion and backlash have significant influences on the load sharing behaviours of the concentric torque-split face gear transmission.
\end{abstract}

\section{Introduction}

The concentric torque-split face gear transmission, shown in Figure 1, has promising use in the rotorcraft which keep seeking ways to transmit high power through the lowest weight. Extensive patents about the concentric torque-split face gear transmission have been carried out [1-3]. Roberto et al. [4] designed the load sharing structure of a drive pinion that floats in the direction of the axes of face gears. Gmirya et al. [5] divided the input torque into multiple kinematic paths to provide a transmission system with relatively small size and lightweight. The gear sizes of the concentric torquesplit face gear transmission are decreased by the torque splitting of the face gears and idlers. The transmission system provides an inherent capability to handle high transmission ratio for the geometry of the face gears. The unique characteristics enable its effective application on the rotorcraft transmission.

To achieve the desired face gear transmission performance, extensive studies have been carried out. Litvin is one of the first persons to explore the design, generation, and tooth contact analysis of the orthogonal face gear drives with a spur involute pinion [6-9]. Claudio [10] and Jin-yuan Tang [11] developed approaches for the modified geometry of face gear drive to reduce the sensitivity of the gear drive to misalignments. Isamu [12] and Sandro [13] investigated the effective engagement area under the designed parameter. Meng Peng [14] and Hu [15] studied the dynamic behaviours of face gear drives. And for the gear transmission with flexible gear bodies, many types of models have been established: shaft element model [16, 17], 3D finite element model [17-21], and segment model [22-24].

However, limited investigations have been done on the load sharing behaviours of the concentric torque-split face gear transmission. The existence of machining errors, misalignment of gears, and asymmetric power transmitting path result in an uneven load sharing between the two face gears and between the two idlers. A thorough understanding of the load sharing behaviours of the concentric torque-split face gear transmission is important. Experimental studies on the load sharing behaviours of the concentric torquesplit face gear transmission have been done by Robert [25, 26]. Nevertheless, we still need a simple method other than experiment to investigate the load sharing behaviours of the concentric torque-split face gear transmission.

In this article, based on the force analysis of each component, a robust and rapid quasistatic analysis model of the concentric torque-split face gear transmission is established. The analytical model is a hybrid of lumped parameter and finite element. This analytical model enables rapid simulations of 


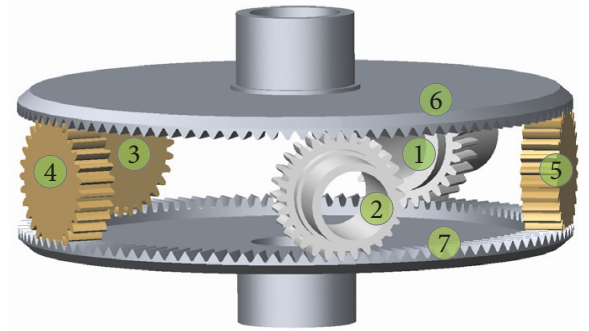

FIGURE 1: The concentric torque-split face gear transmission.

quasistatic load sharing behaviours of the concentric torquesplit face gear transmission. Considering the flexible face gear bodies, backlash, and support stiffness, the load sharing behaviours are investigated through numerical quasistatic simulations. The load sharing analysis method proposed in this paper provides guidance on searching for reasonable design parameters for the concentric torque-split face gear transmission.

\section{Uneven Load Sharing Problem}

The concentric torque-split face gear transmission (Figure 1) comprises two face gears (gears 6 and 7) rotating about a common axis, two input pinions 1 and 2 rotating about a respective axes perpendicular to the axes of rotation of the face gears, and two idlers (gears 3 and 4), and one tail rotor (gear 5) rotating about respective axes substantially coplanar with the axes of the pinions.

This design is configured with the two face gears located face-to-face one over the other. The two input pinions drive in between the two face gears from each side. The two idlers and the tail rotor recombine most of the torque that fed to the lower face gear from the pinions in the upper face gear, while the other torque is transmitted to the tail shaft through the tail rotor. The two face gears are totally the same, the two input pinions are totally the same, and the two idlers are also entirely the same. The input pinions, idlers, and tail rotor are standard spur gears with the same modulus, tooth numbers and pressure angle. These spur gears are arranged on the circumference of the face gears, and the position angle between the adjacent spur gears is $2 \pi / 5$.

The torques of pinions 1 and 2 are transmitted to the output shaft of the upper face gear 6 through two paths. The upper path through the upper meshes of pinions to the upper face gear (from gears 1 and 2 to gear 6 ), the lower path through the lower meshes of pinions to the lower face gear, then to the idlers and tail rotor, and finally through the upper meshes of the idlers and tail rotor to the upper face gear (from gears 1 and 2 to gear 7 , then to gears 3,4 and 5 , and then to gear 6).

Figure 2 illustrates the power flow of the concentric torque-split face gear transmission. Where $k_{t}$ is the average mesh stiffness of gear pairs, $k_{z}$ is the axial stiffness of the face gear rim in the position that the face gear meshes with

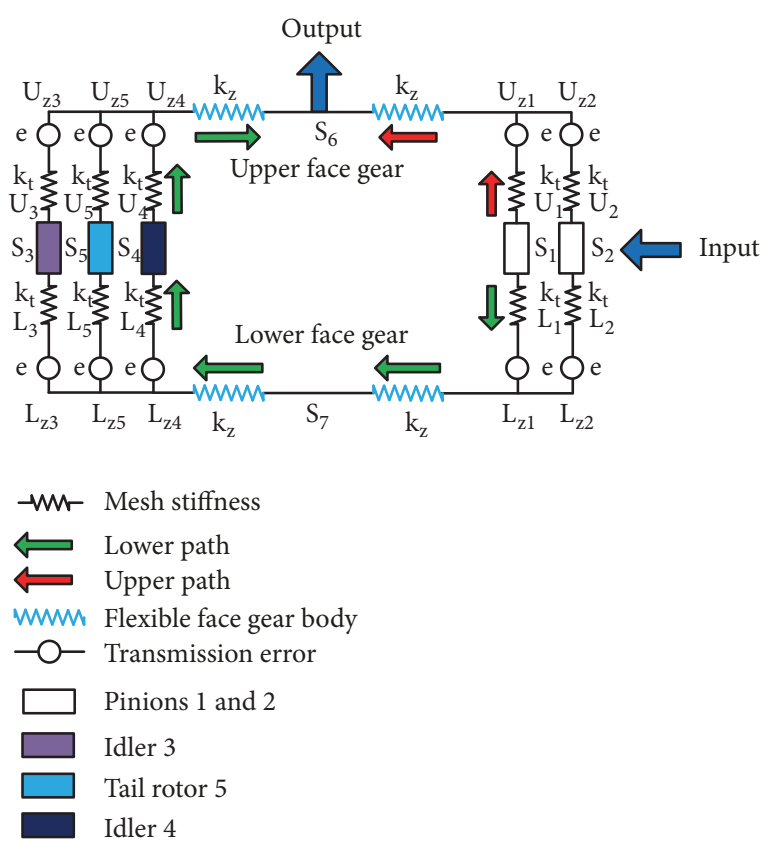

FIgURE 2: The power flow.

the spur gear, $k_{1} \sim k_{7}\left(k_{1}=k_{2}, k_{3}=k_{4}=k_{5}, k_{6}=k_{7}\right)$ are the support stiffness of the gears that are not shown for clarity, $S_{1} \sim S_{7}$ are the support deformations of gears, and $e$ is the unloaded transmission error. Because the spur gears are exactly the same and the two face gears are also exactly the same, so the average mesh stiffness of all gear pairs is the same, and all the axial stiffness of face gear rim in the positions that the face gear meshes with the spur gears is the same. $L_{z 1} \sim L_{z 5}$ are the deformations of the lower face gear rim in the positions that the face gear meshes with the spur gears, $U_{z 1} \sim U_{z 5}$ are the deformations of the upper face gear rim in the positions that the face gear meshes with the spur gears, $L_{1} \sim L_{5}$ are the deformations of the lower meshes of the spur gears, and $U_{1} \sim U_{5}$ are the deformations of the upper meshes of the spur gears.

Due to the elasticity and the machining error, the two paths will produce elastic deformations and rigid gear body displacements when the torques are applied to the input pinions. The upper path, which is shown in Figure 2 marked by the red arrows, is the path from the input pinions to the output shaft. The upper path goes just through one mesh deformation, one transmission error, and one gear body deformation, while the lower path that shown in Figure 2 marked by the green arrows is the path from the input pinions to the output shaft. The lower path goes through seven mesh deformations, seven transmission errors, and three gear body deformations. It is obvious that the lower path is much "longer" than the upper path. The two paths are asymmetric unless they have been designed carefully.

To explain the uneven load sharing problem of the two paths more clearly, the equivalent displacement and the equivalent stiffness are defined. The deformations and displacements of two paths are projected to the line of 
action of the upper and lower meshes of the spur gears. The equivalent displacement can be expressed as

$$
\begin{aligned}
\delta_{U}= & U_{1}-\left(S_{1}+S_{6}+U_{z 1}\right) \cdot \sin \alpha-e \\
\delta_{L}= & L_{1}+L_{3}+U_{3}-\left(L_{z 1}+L_{z 3}+U_{z 3}+S_{6}+S_{7}\right) \\
& \cdot \sin \alpha+S_{1} \cdot \sin \alpha-3 e
\end{aligned}
$$

where $\delta_{U}, \delta_{L}$ are the equivalent displacement of the upper and lower paths, respectively. $\delta_{U}=\delta_{L}$ is obtained under the compatibility condition of deformation. $\alpha$ is the pressure angle which is equivalent to the angle between the line of action and the transverse plane of the face gear.

The equivalent stiffness of the upper and lower paths can be expressed as

$$
\begin{aligned}
& K_{U}=\frac{2 k_{1} k_{6} k_{z} k_{t} \cdot \sin \alpha}{\left(k_{1} k_{z} \cdot \sin \alpha+k_{t} k_{z}+k_{1} k_{t} \cdot \sin \alpha\right) k_{6}+2 k_{1} k_{z} k_{t}} \\
& K_{L}=\frac{6 k_{1} k_{6} k_{z} k_{t} \cdot \sin \alpha}{3\left(k_{1} k_{z} \cdot \sin \alpha+k_{t} k_{z}+k_{1} k_{t} \cdot \sin \alpha\right) k_{6}+12 k_{1} k_{z} k_{t}+4\left(k_{z} \cdot \sin \alpha+k_{t}\right) k_{1} k_{6}}
\end{aligned}
$$

where $K_{U}, K_{L}$ are the equivalent stiffness of the upper and lower paths, respectively.

For the convenience of understanding, the load of the two paths is represented by the mesh force of the upper and lower meshes which can be expressed as

$$
\begin{gathered}
F_{U}=\delta_{U} \cdot K_{U} \\
F_{L}=\delta_{L} \cdot K_{L}
\end{gathered}
$$

The load sharing coefficient of the two paths can be expressed as

$$
\begin{aligned}
\xi & =\frac{F_{U}}{F_{L}}=\frac{\delta_{U} \cdot K_{U}}{\delta_{L} \cdot K_{L}} \\
& =\frac{\left(7 k_{z}+3 k_{t}\right) k_{1} k_{6} \cdot \sin \alpha+3\left(4 k_{1}+k_{6}\right) k_{z} k_{t}+4 k_{1} k_{6} k_{t}}{3\left(k_{1} k_{z} \cdot \sin \alpha+k_{t} k_{z}+k_{1} k_{t} \cdot \sin \alpha\right) k_{6}+6 k_{1} k_{z} k_{t}}
\end{aligned}
$$

In most cases, the load sharing coefficient $\xi$ of the two paths is not equal to 1 unless the average mesh stiffness, the support stiffness, and the axial stiffness of the rim of the face gear have been designed carefully. On the other hand, the mesh stiffness is a time-varying parameter, and the mesh phase of the time-varying mesh stiffness of all gear pairs may be different due to the odd and even tooth number designs of spur gears. So it is impossible to gain an even load sharing of the concentric torque-split face gear transmission.

In the lower path, it is worthy to note that the torque is split to three subpaths by the two idlers and the tail rotor. The backlash difference of the lower meshes of the two idlers results in an uneven load sharing of the two idlers when the torque that fed to the lower face gear is transmitting to the upper face gear.

\section{Quasistatic Model}

3.1. The Hybrid 3D Finite Element/Lumped Parameter Model. In the application of helicopter transmission, the maximum diameter of the face gear can be as much as $600 \mathrm{~mm}$. The face gear body is easy to deform under load and the deformation cannot be ignored in the load sharing behaviour analysis. Thus, the face gear body and its shaft are discrete into finite elements so that the deformation under load is allowed. The load sharing analysis results are more accurate by considering the deformation of the face gear bodies.

The hybrid 3D finite element/lumped parameter model of the concentric torque-split face gear transmission is shown in Figure 3. The quasistatic load sharing analytical model aims at predicting the load sharing behaviours among different paths. This model includes the flexible face gear bodies, backlash, bearings, shafts, and time-varying mesh stiffness. It is a hybrid of lumped parameter and finite element and enables rapid simulations of quasistatic load sharing analysis of the torquesplit face gear transmission.

The flexible face gear bodies are simulated with 3D finite element models ( 8 node brick elements). The effects of the factors on the load sharing behaviours are investigated through numerical quasistatic simulations. The nodes of output shaft at the bearing location are fixed in the rotation direction of the output shaft. Also, the nodes of two face gear shafts at the bearing locations are elastically constrained in the radial and axil direction. The stiffness of the elastic constrains is equal to the support stiffness of bearings. The gear bodies of the input pinions, idlers, and tail rotor are regarded as rigid disks with radial elastic constraints whose stiffness is equal to its support stiffness.

In the hybrid 3D finite element/lumped parameter model, the force equations of gears are established, respectively. Figure 4 illustrates the connection between the spur gear and the 3D finite element nodes of the face gear. The mesh between the engaged teeth of the spur gear and the face gear is defined by time-varying mesh stiffness $k(t)$ and $k(t+\lambda \cdot \Psi / 2)$. The mesh force is applied on the face gear through the five nodes shown in Figure 4. As the diameter of the face gear body is much larger than the size of the tooth width, the time-varying mesh force is applied evenly on the five nodes along the tooth width of the face gear. The displacement of the face gear along the line of action is the average of the displacements of the five nodes.

3.2. The Time-Varying Mesh Stiffness. The time-varying mesh stiffness is the main excitation of the gear transmission system. Because of the variation of the mesh positions and the 


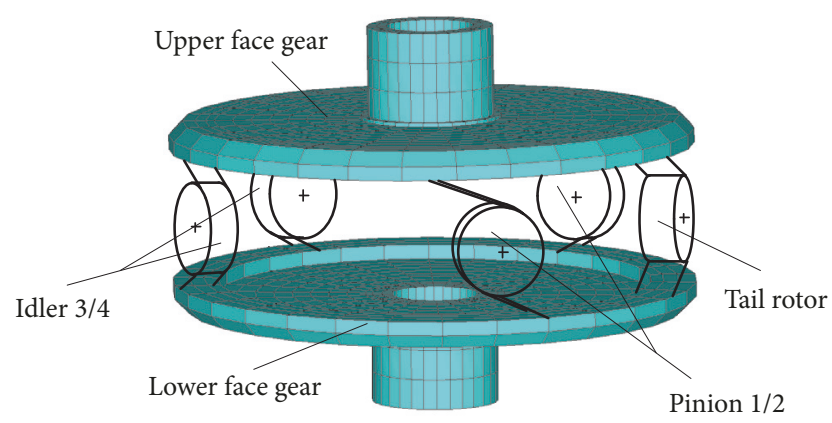

Figure 3: The hybrid 3D finite element/lumped parameter model (for clarity, supports are not shown).

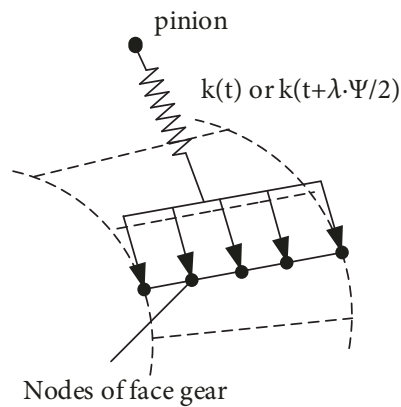

FIGURE 4: The connection between the spur gear and the face gear $3 \mathrm{D}$ finite element nodes.

engaged tooth number, the mesh stiffness of the gear transmission varies periodically. Moreover, the tooth surface of the face gear is complex, and the tooth thickness varies along the tooth width direction. Thus, the analytical solution of the time-varying mesh stiffness of the face gear transmission is hard to obtain. In this section, the time-varying mesh stiffness of the face gear transmission is calculated by a finite element method.

Figure 5 illustrates the model of the finite element method that is used for the calculation of the time-varying mesh stiffness. The calculation domain is the time of the whole meshing circle of gear tooth 3 . The whole meshing circle is divided into 21 meshing positions. Each meshing position will carry on a loaded tooth contacted analysis (LTCA) by commercial software (ANSYS). The contact ratio of the face gear transmission can be 2 3 due to the deformation of the gear tooth, so the finite element model is established with 5 teeth to ensure all contact tooth pairs are involved in LTCA. A reference point is set in the center of rotation of the spur gear, and it is coupled with the spur gear's inner ring. The rim of the face gear is fixed, and a torque of $300 \mathrm{~N} \cdot \mathrm{m}$ is applied to the reference point. The stiffness $k_{t}$ of each meshing position can be derived by

$$
k_{t}=\frac{T}{r_{p b}^{2} \theta_{p}}
$$

where $r_{p b}$ is the base circle radius of the spur gear and $\theta_{p}$ is the rotation angle of the spur gear under torque.

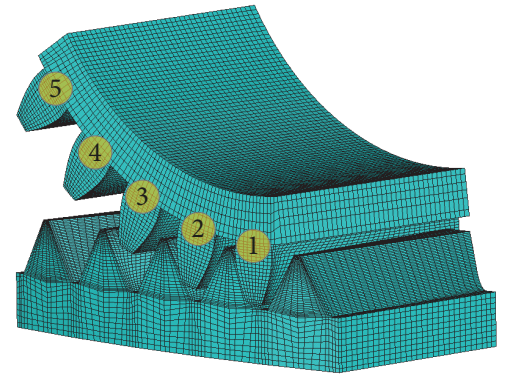

FIGURE 5: Finite element model.

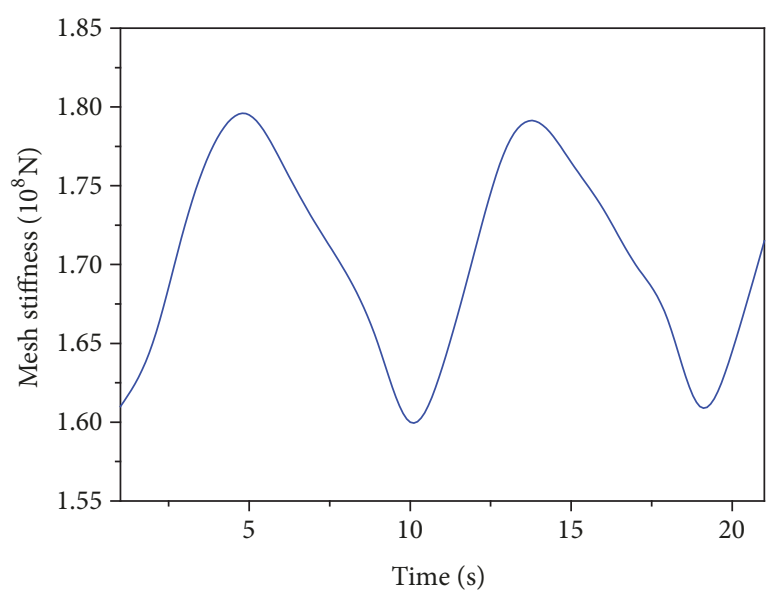

FIGURE 6: Time-varying mesh stiffness.

After the mesh stiffness of all the meshing positions are calculated, the time-varying mesh stiffness curve of the face gear transmission is obtained in Figure 6. The time-varying mesh stiffness curve will be applied on the quasistatic model in the following sections.

Due to the deformation of the gear tooth, the whole mesh circle $\Psi$ is 19 seconds rather than 21 seconds [27] as shown Figure 6 . The ten gear pairs of the system have the same design parameters. However, the mesh phase of the ten gear pairs is different. When the tooth number of the spur gear is odd, the mesh phase difference of the upper and lower meshes of the spur gear is half of the whole mesh circle. Assuming that the lower mesh stiffness of the odd tooth number design is the mesh stiffness shown in Figure 6, then the starting time of the upper mesh stiffness should be the 9 seconds. When the tooth number of the spur gear is even, the mesh phases of the upper and lower meshes of the spur gears are the same. Under the design in Section 2, the lower mesh phases of the lower meshes of the five spur gears are exactly the same.

3.3. The Force Analysis of Gears. The coordinate systems are illustrated in Figure 7. As the maximum radius of the face gear is much larger than the size of the tooth width, the coordinate system $\left(S_{j i}, i=1 \sim 5\right)$ is set at the midpoint of the tooth width of each face gear. And each face gear establishes its coordinate system $S_{j}(j=6 \sim 7)$, where $O_{j i}$ should be on the plane of 


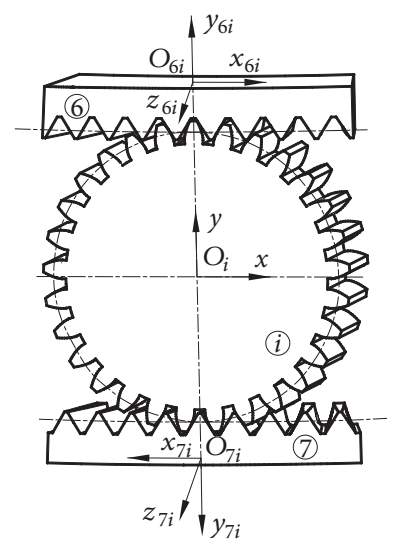

(a)

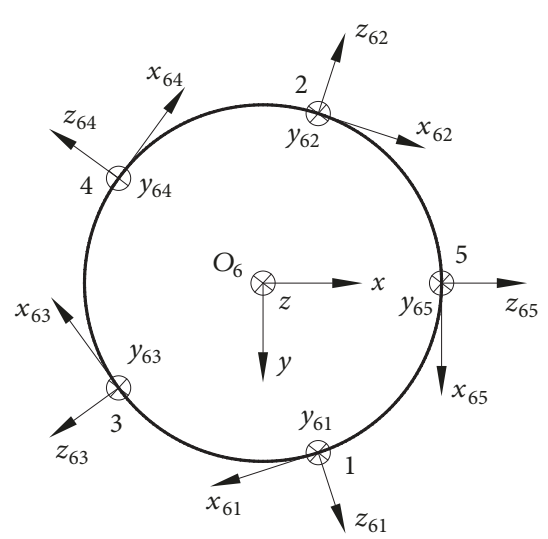

(b)

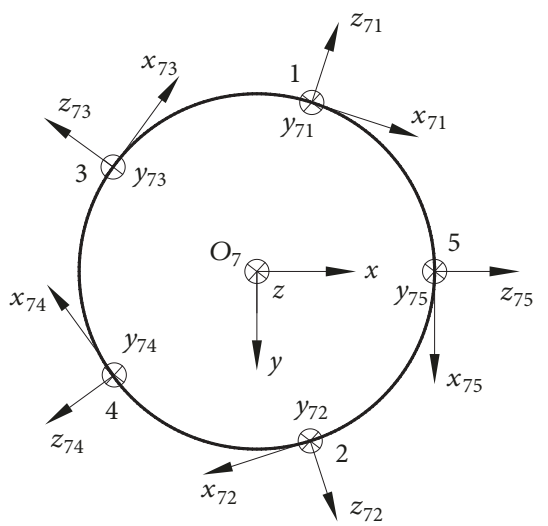

(c)

Figure 7: The coordinate system: (a) spur gear $i$; (b) upper face gear 6 (the view from the spur gear $i$ to the face gear); (c) lower face gear 7 (the view from the spur gear $i$ to the face gear).

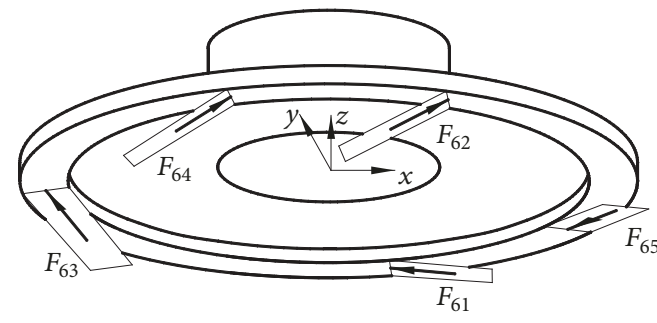

(a)

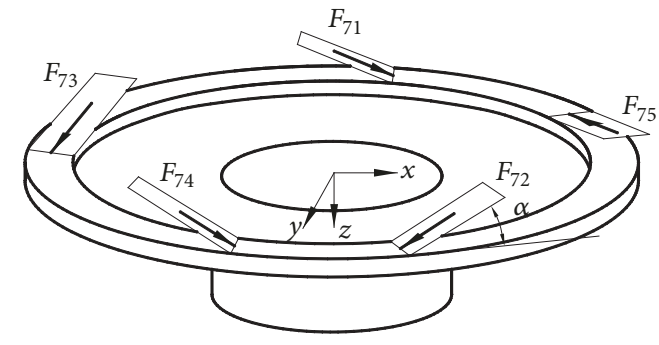

(b)

FIGURE 8: Schematic diagram of force analytical model of the face gears: (a) upper face gear 6; (b) lower face gear 7.

the face gear that is tangent to the reference circle of the spur gear. However, $O_{j i}$ is placed on the rim for clarity.

3.3.1. The Face Gears. The schematic diagram of force analytical models of the two face gears is shown in Figure 8. For each face gear, imposing the axial equilibrium condition, the following equations are derived:

$$
\begin{gathered}
F_{j 1} \cdot \sin \alpha+F_{j 2} \cdot \sin \alpha+F_{j 3} \cdot \sin \alpha+F_{j 4} \cdot \sin \alpha+F_{j 5} \\
\cdot \sin \alpha=k_{j} \cdot z_{j}
\end{gathered}
$$

where $F_{j i}(i=1 \sim 5, j=6,7)$ is the mesh force between the spur and the face gear, $\alpha$ is the press angle, and $k_{j}$ and $z_{j}$ are the support stiffness and the axial support deformation of the face gear, respectively.

It is noteworthy that the flexible face gear body cannot be neglected due to its large size and disk-like structure. The deformations of the five positions that the face gear meshes with the spur gears are the results of the forces acting on them. The face gear body is discretized by 8 node brick elements. The stiffness matrix is derived by assembling all node numbers and element numbers in the face gear coordinate system. Imposing the boundary conditions, the complete compliance matrix of all nodes is obtained by inversing the stiffness matrix. By deleting the row and column of the nodes other than the five nodes of the five positions of the complete compliance matrix, the compliance matrix $\left[\mathrm{rou}_{j}\right]_{75 \times 75}$ is obtained. Thus, the relationship between forces and displacements are established by the compliance matrix as follows:

$$
\left[\operatorname{rou}_{j}\right]_{75 \times 75} \cdot\left[F_{j}\right]_{75 \times 1}=\left[\delta_{j}\right]_{75 \times 1}
$$

where $\left[\mathrm{rou}_{\mathrm{j}}\right]_{75 \times 75}$ is the compliance matrix of the nodes on the five positions that the face gear meshes with the spur gears. $\left[F_{j}\right]_{75 \times 1}$ and $\left[\delta_{j}\right]_{75 \times 1}$ are the force vector and displacement vector of the nodes on the five positions, respectively, in the coordinate system $S_{j}$. It should be noted that the time-varying mesh force is applied evenly to the five nodes of each position, and the displacement of point $O_{j i}$ on the face gear is the average displacements of the five nodes.

To obtain $\left[F_{j}\right]_{75 \times 1}$, the mesh force $F_{j i}$ between the spur gear and the face gear should be projected to the coordinate axis of the coordinate systems $S_{j i}$. Because the compliance matrix $\left[\mathrm{rou}_{\mathrm{j}}\right]_{75 \times 75}$ is calculated in the coordinate systems $S_{j}$, so the projection should also be transformed to $S_{j}$ by $M_{j i}$ as follows:

$$
\begin{aligned}
& F_{6}^{(\gamma)}=\left(F_{6 i} \cos \alpha, F_{6 i} \sin \alpha, 0\right) \cdot M_{6 i} \\
& F_{7}^{(\gamma)}=\left(\zeta \cdot F_{7 i} \cdot \cos \alpha, \zeta \cdot F_{7 i} \cdot \sin \alpha, 0\right) \cdot M_{7 i}
\end{aligned}
$$


where $\gamma=1 \sim 5$ represent the five nodes along the tooth width of the face gear, $\zeta$ is negative as $i=3,4,5$, and $\zeta$ is positive as $i=1,2$.

The connection between the engaged teeth of the spur gear and the face gear are defined in Section 3.1. In the application of helicopter transmission, the maximum diameter of the face gear can be as much as $600 \mathrm{~mm}$, while the tooth width is $52 \mathrm{~mm}$. The diameter of the face gear body is much larger than the size of the tooth width, so the time-varying mesh force is applied evenly to the five nodes along the tooth width of the face gear as follows:

$$
\begin{aligned}
& {\left[F_{j}\right]_{75 \times 1} }=\frac{1}{5}\left[F_{j}^{(1)}, \ldots, F_{j}^{(1)}, F_{j}^{(2)}, \ldots, F_{j}^{(2)}, F_{j}^{(3)}, \ldots, F_{j}^{(3)},\right. \\
&\left.F_{j}^{(4)}, \ldots, F_{j}^{(4)}, F_{j}^{(5)}, \ldots, F_{j}^{(5)}\right]_{75 \times 1}^{T}
\end{aligned}
$$

where $F_{j}^{(\gamma)}$ are defined by $(10)$ and $(11) ; F_{j}^{(\gamma)}, \ldots, F_{j}^{(\gamma)}$ is a brief of $F_{j}^{(\gamma)}, F_{j}^{(\gamma)}, F_{j}^{(\gamma)}, F_{j}^{(\gamma)}, F_{j}^{(\gamma)}$.

The displacement vector $\left[\delta_{j}\right]_{75 \times 1}$ of the five nodes on the five positions can be expressed as follows:

$$
\begin{aligned}
& {\left[\delta_{j}\right]_{75 \times 1}=\left[x_{j 1}^{(1)}, y_{j 1}^{(1)}, z_{j 1}^{(1)}, \ldots, x_{j 1}^{(5)}, y_{j 1}^{(5)}, z_{j 1}^{(5)}, x_{j 2}^{(1)}, y_{j 2}^{(1)}, z_{j 2}^{(1)},\right.} \\
& \quad \ldots, x_{j 2}^{(5)}, y_{j 2}^{(5)}, z_{j 2}^{(5)}, x_{j 3}^{(1)}, y_{j 3}^{(1)}, z_{j 3}^{(1)}, \ldots, x_{j 3}^{(5)}, y_{j 3}^{(5)}, z_{j 3}^{(5)}, x_{j 4}^{(1)}, \\
& y_{j 4}^{(1)}, z_{j 4}^{(1)}, \ldots, x_{j 4}^{(5)}, y_{j 4}^{(5)}, z_{j 4}^{(5)}, x_{j 5}^{(1)}, y_{j 5}^{(1)}, z_{j 5}^{(1)}, \ldots, x_{j 5}^{(5)}, y_{j 5}^{(5)}, \\
& \left.\quad z_{j 5}^{(5)}\right]_{75 \times 1}^{T}
\end{aligned}
$$

The displacement of $O_{j i}$ in the coordinate system $S_{j}$ can be expressed as follows:

$$
\begin{aligned}
x_{j i}^{S_{j}} & =\frac{1}{5}\left(x_{j i}^{(1)}+\cdots+x_{j i}^{(5)}\right), \\
y_{j i}^{S_{j}} & =\frac{1}{5}\left(y_{j i}^{(1)}+\cdots+y_{j i}^{(5)}\right), \\
z_{j i}^{S_{j}} & =\frac{1}{5}\left(z_{j i}^{(1)}+\cdots+z_{j i}^{(5)}\right)
\end{aligned}
$$

which will be transformed to the coordinate systems $S_{j i}$ by $M_{i j}$ as follows:

$$
\left[x_{j i}, y_{j i}, z_{j i}\right]=\left[x_{j i}^{S_{j}}, y_{j i}^{S_{j}}, z_{j i}^{S_{j}}\right] \cdot M_{i j}
$$

Again, imposing the equilibrium condition in the torsion direction of the lower face gear, the following equation is obtained:

$$
\begin{aligned}
& \left(F_{71} \cdot r_{c 7}+F_{72} \cdot r_{c 7}\right) \cdot \cos \alpha \\
& \quad=\left(F_{73} \cdot r_{c 7}+F_{74} \cdot r_{c 7}+F_{75} \cdot r_{c 7}\right) \cdot \cos \alpha
\end{aligned}
$$

where $r_{c 7}$ is the pitch circle radius of the lower face gear.

3.3.2. The Input Pinions. The schematic diagram of the force analytical model of pinion $m(m=1,2)$ is shown in Figure 9.

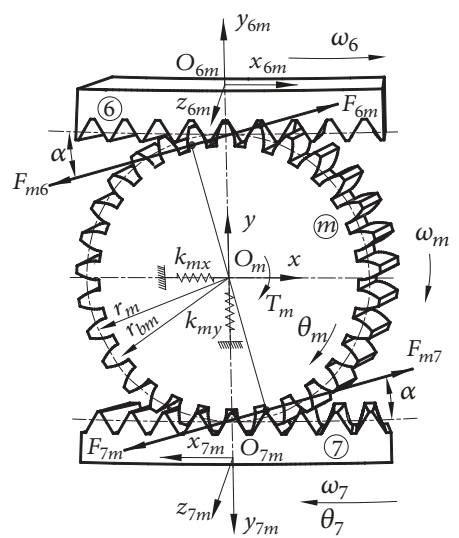

FIGURE 9: Schematic diagram of the force analytical model of the pinion.

Imposing the equilibrium condition in the torsion direction, the following equation is obtained:

$$
F_{m 6} \cdot r_{b m}+F_{m 7} \cdot r_{b m}=T_{m}
$$

where $F_{m j}(j=6,7)$ is the mesh force of the face gear, $T_{m}$ is the input torque of pinion $m$, and $r_{b m}$ is the radius of base circle of pinion $m$.

Imposing the equilibrium conditions in the direction of $x_{m}$ and $y_{m}$, the following equations are derived:

$$
\begin{gathered}
F_{m 7} \cdot \cos \alpha-F_{m 6} \cdot \cos \alpha-k_{m x} \cdot x_{m}=0 \\
F_{m 7} \cdot \sin \alpha-F_{m 6} \cdot \sin \alpha-k_{m y} \cdot y_{m}=0
\end{gathered}
$$

where $k_{m x}, k_{m y}$ are the support stiffness of input pinion $m$ in the direction of $x_{m}$ and $y_{m}$, respectively.

Considering the time-varying mesh stiffness, the following equations are obtained by the mesh deformation condition:

$$
\begin{aligned}
& F_{m 6}=k\left(t+\lambda \cdot \frac{\Psi}{2}\right) \cdot\left(\theta_{m} \cdot r_{b m}-\Delta_{6 m}-\sigma_{6 m}\right) \\
& F_{m 7}=k(t) \cdot\left(\theta_{m} \cdot r_{b m}-\theta_{7} \cdot r_{c 7} \cdot \cos \alpha-\Delta_{7 m}-\sigma_{7 m}\right)
\end{aligned}
$$

where $k(t)$ is the time-varying mesh stiffness, $\lambda=0$ or 1 , when the tooth number of the spur gear is odd, $\lambda=1$, when the tooth number of the spur gear is even, $\lambda=0, \sigma_{j m}$ is the backlash of the upper and lower meshes of pinions, $\theta_{m}, \theta_{7}$ are the twist angle of pinion $m$ and face gear 7 , respectively, $\Delta_{j m}$ is the displacement in the line of action, and $\Delta_{j m}$ is defined by (22) and (23) as follows:

$$
\begin{aligned}
\Delta_{6 m}= & x_{6 m} \cdot \cos \alpha+y_{6 m} \cdot \sin \alpha+z_{6} \cdot \sin \alpha \\
& -\left(x_{m} \cdot \cos \alpha+y_{m} \cdot \sin \alpha\right) \\
\Delta_{7 m}= & x_{m} \cdot \cos \alpha+y_{m} \cdot \sin \alpha+x_{7 m} \cdot \cos \alpha+y_{7 m} \\
& \cdot \sin \alpha+z_{7} \cdot \sin \alpha
\end{aligned}
$$

where $x_{j m}, y_{j m}$ are the displacement of the face gears along the coordinate axis of $x_{j m}$ and $y_{j m}$, respectively. 


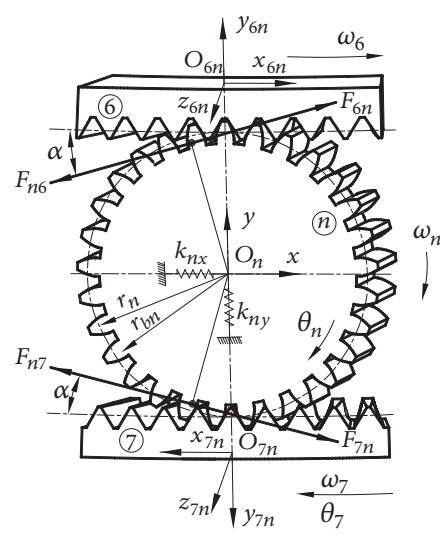

(a)

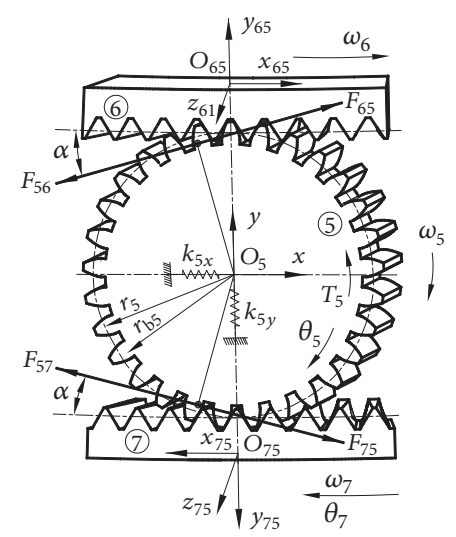

(b)

FIgURE 10: Schematic diagram of force analytical model of the idlers and tail rotor: (a) idlers 3 and 4; (b) tail rotor 5.

3.3.3. The Idlers/Tail Rotor. The schematic diagram of the force analytical model of idlers 3 and 4 and tail rotor 5 are shown in Figure 10. The equilibrium equation is derived as follows:

$$
F_{n 6} \cdot r_{b n}-F_{n 7} \cdot r_{b n}=0
$$

where $F_{n j}(n=3,4)$ are the mesh force of each face gear and $r_{b n}$ is the base circle radius of idler $n$.

And the equilibrium equations in the direction of $x_{n}$ and $y_{n}$ are derived as follows:

$$
\begin{array}{r}
-F_{n 7} \cdot \cos \alpha-F_{n 6} \cdot \cos \alpha-k_{n x} \cdot x_{n}=0 \\
F_{n 7} \cdot \sin \alpha-F_{n 6} \cdot \sin \alpha-k_{n y} \cdot y_{n}=0
\end{array}
$$

where $k_{n x}, k_{n y}$ are the support stiffness of idler $n$ in the direction of $x_{n}$ and $y_{n}$, respectively.

The mesh deformation equations of the lower and upper meshes of idler $n$ are derived as follows:

$$
\begin{aligned}
& F_{n 6}=k\left(t+\lambda \cdot \frac{\Psi}{2}\right) \cdot\left(\theta_{n} \cdot r_{b n}-\Delta_{6 n}-\sigma_{6 n}\right) \\
& F_{n 7}=k(t) \cdot\left(\theta_{7} \cdot r_{c 7} \cdot \cos \alpha-\theta_{n} \cdot r_{b n}-\Delta_{7 n}-\sigma_{7 n}\right)
\end{aligned}
$$

where $\theta_{n}$ is the twist angle of idler $n$ and $\Delta_{j n}$ are defined by (29) and (30):

$$
\begin{aligned}
\Delta_{6 n}= & x_{6 n} \cdot \cos \alpha+y_{6 n} \cdot \sin \alpha+z_{6} \cdot \sin \alpha \\
& -\left(x_{n} \cdot \cos \alpha+y_{n} \cdot \sin \alpha\right) \\
\Delta_{7 n}= & -x_{n} \cdot \cos \alpha+y_{n} \cdot \sin \alpha-x_{7 n} \cdot \cos \alpha+y_{7 n} \\
& \cdot \sin \alpha+z_{7} \cdot \sin \alpha
\end{aligned}
$$

where $x_{j n}, y_{j n}$ are the displacement of the face gears along $x_{j n}$, $y_{j n}$, respectively.
The similar force equations of the tail rotor 5 (Figure $10(\mathrm{~b}))$ are also derived as follows:

$$
\begin{aligned}
& F_{56} \cdot r_{b 5}-F_{57} \cdot r_{b 5}=T_{5} \\
& -F_{57} \cdot \cos \alpha-F_{56} \cdot \cos \alpha-k_{5 x} \cdot x_{5}=0 \\
& F_{57} \cdot \sin \alpha-F_{56} \cdot \sin \alpha-k_{5 y} \cdot y_{5}=0 \\
& F_{56}=k\left(t+\lambda \cdot \frac{\Psi}{2}\right) \cdot\left(\theta_{5} \cdot r_{b 5}-\Delta_{65}-\sigma_{65}\right) \\
& F_{57}=k(t) \cdot\left(\theta_{7} \cdot r_{c 7} \cdot \cos \alpha-\theta_{5} \cdot r_{b 5}-\sigma_{75}\right)
\end{aligned}
$$

where $T_{5}$ is the torque that fed to the tail rotor, $\sigma_{j 5}$ is the backlash of the upper and lower meshes of the tail rotor, and $\Delta_{j 5}$ are defined as follows:

$$
\begin{aligned}
\Delta_{65}= & x_{65} \cdot \cos \alpha+y_{65} \cdot \sin \alpha+z_{6} \cdot \sin \alpha \\
& -\left(x_{5} \cdot \cos \alpha+y_{5} \cdot \sin \alpha\right) \\
\Delta_{75}= & -x_{5} \cdot \cos \alpha+y_{5} \cdot \sin \alpha-x_{75} \cdot \cos \alpha+y_{75} \\
& \cdot \sin \alpha+z_{7} \cdot \sin \alpha
\end{aligned}
$$

3.4. Load Sharing and Load Distribution. The procedure of the Quasistatic load sharing calculation is illustrated in Figure 11 as follows.

In the force analysis above, there are numerous variables and independent equations. There are 178 variables which are composed of 10 mesh forces $\left(F_{j i}\right)$ of gear pairs, 2 axial support deformations $\left(z_{j}\right)$ of the two face gears, 1 twist angle $\left(\theta_{7}\right)$ of the lower face gear, 5 twist angles $\left(\theta_{i}\right)$ of the spur gears, 5 support displacements $\left(x_{i}\right.$ and $\left.y_{i}\right)$ of the spur gears, and the 150 displacements $\left(\left[\delta_{j}\right]_{75 \times 1}\right)$ of the nodes of the face gears that connected to the spur gears. Also there are 178 independent equations which are composed of 153 equations (see (8)-(11) and (16)) in the force analysis of the face gears, 10 equations (see (17)-(21)) in the force analysis of the input pinions, 10 equations (see (24)-(28)) in the force analysis of the idlers, and 5 equations (see (31)-(35)) in the force analysis of the tail 


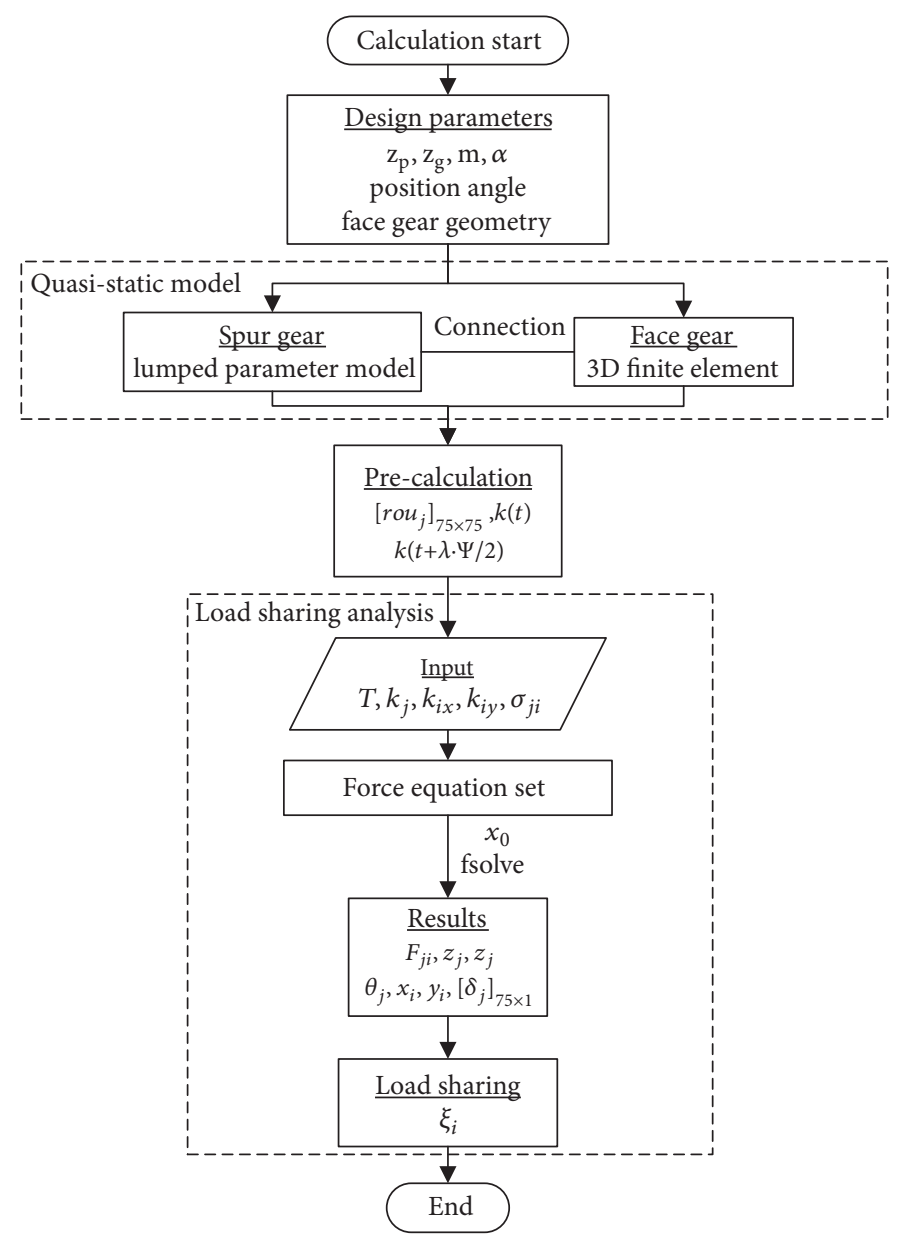

FIGURE 11: Procedure of the quasistatic load sharing calculation.

rotor. The number of the variables is equal to the number of the independent equations, so the unknown variables can be obtained by solving the equation set composed by the 178 independent equations. And the load sharing coefficients of the two face gears that mesh with the input pinions can be expressed as

$$
\begin{aligned}
& \xi_{1}=\frac{F_{17}}{F_{16}} \\
& \xi_{2}=\frac{F_{27}}{F_{26}}
\end{aligned}
$$

The load distribution among idlers and tail rotor can be expressed as

$$
\begin{aligned}
& \xi_{3}=\frac{F_{36}}{\left(F_{16}+F_{26}\right)} \\
& \xi_{4}=\frac{F_{46}}{\left(F_{16}+F_{26}\right)} \\
& \xi_{5}=\frac{F_{56}}{\left(F_{16}+F_{26}\right)}
\end{aligned}
$$

3.5. Model Validation. The proposed quasistatic load sharing analytical model is tested on the concentric torque-split face gear transmission shown in Figure 1. The concentric torquesplit face gear transmission gears are 2.00 module, with the pinions, idlers, and tail rotor having 23 teeth and the two face gears (defined in Figure 12(a)) having 145 teeth. The input torque is $300 \mathrm{~N} \cdot \mathrm{m}$, and the output torque of the tail rotor is $50 \mathrm{~N} \cdot \mathrm{m}$. By solving the quasistatic model established above, the load sharing between the two face gears and between the two idlers is obtained. In order to assess the accuracy of the proposed load sharing analytical model, the validation was performed on commercial software (ANSYS). The ANSYS model of the concentric torque-split face gear transmission is illustrated in Figure 12(b). The nodes of the face gears and input pinions on the bearing positions are coupled with a reference point respectively. The inner rings of the idlers and tail rotor are also coupled with a reference point respectively. The reference point is set in the center of rotation and it is coupled with a fixed node by spring elements defined by the stiffness that are equal to the support stiffness in their corresponding directions.

Figure 13 illustrates the calculation of the mesh force between the spur gear and the face gear in the ANSYS model. The contact tooth pair number varies in different 
TABLE 1: Model validation results.

\begin{tabular}{lcccccc}
\hline Description & Upper mesh & Lower mesh & Idler 3 & Idler 4 & Tail rotor 5 & Computing time \\
\hline ANSYS model & $61.7 \%$ & $38.3 \%$ & $28.1 \%$ & $28.6 \%$ & $43.3 \%$ & $28.4 \mathrm{hr}$. \\
Quasi-static model & $64.4 \%$ & $35.6 \%$ & $25.8 \%$ & $26.5 \%$ & $46.7 \%$ & $230 \mathrm{sec}$. \\
Difference & $4.4 \%$ & $7.0 \%$ & $8.2 \%$ & $7.3 \%$ & $7.9 \%$ & $99.98 \%$ \\
\hline
\end{tabular}

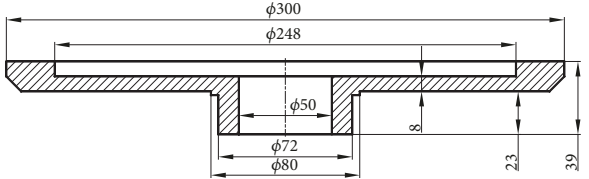

(a)

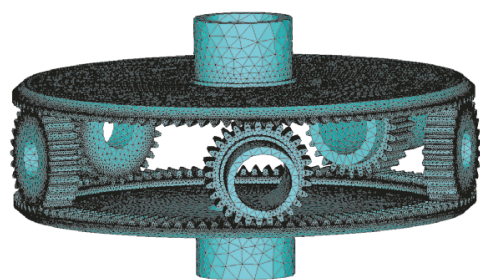

(b)

FIgURE 12: (a) Face gear geometry (in mm) and (b) ANSYS finite element model.

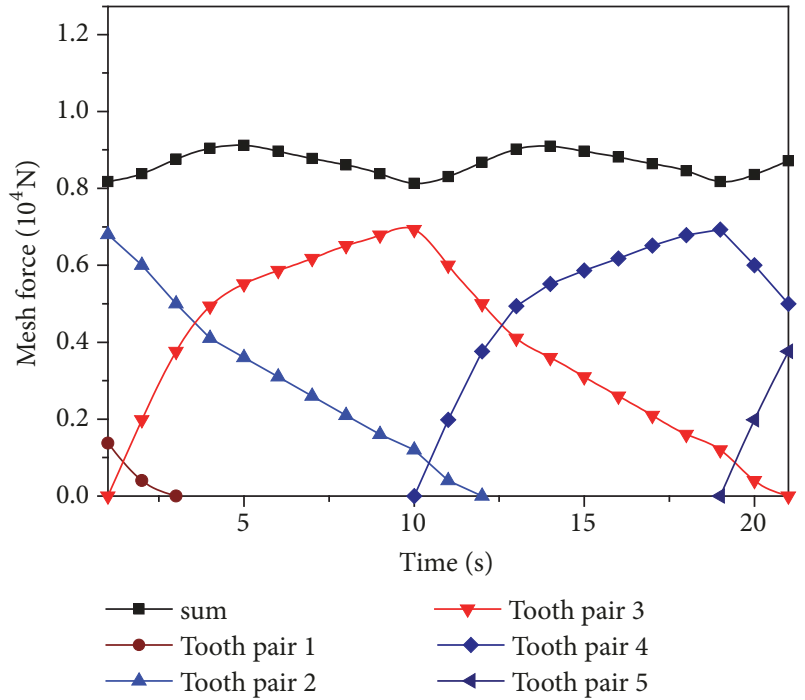

FIGURE 13: Calculation of the mesh force in the ANSYS model.

mesh positions. The mesh force between the spur gear and face gear is the sum of the mesh force of all contact tooth pair at an instant mesh position.

The mesh force calculated by the quasistatic model (QM) and the ANSYS model (AM) is illustrated in Figure 14.

In the quasistatic model, the accurate time-varying mesh stiffness and the stiffness matrices of the face gear bodies are precalculated and stored. So a lot of computing time is saved. Moreover, the displacements of all components are projected to the direction of the line of action. The deformation equations and equilibrium equations are established. The results of the quasistatic load sharing analytical model and ANSYS finite element model of the torque-split face gear transmission are shown in Table 1 . The maximum difference between the results obtained by the quasistatic load sharing analytical model and the ANSYS model is $8.2 \%$, while the computing time of the ANSYS model is $99.98 \%$ longer than the quasistatic load sharing analytical model.

\section{Parameter Analysis}

The support stiffness of pinion is an important parameter for the load sharing design of the concentric torque-split face gear transmission. It influences the load distribution between the upper and lower face gears. The backlash is another important load sharing design parameter that affects the load sharing of the two face gears and the two idlers. Moreover, the parity of the tooth number of the spur gear results in a mesh phase difference between the upper and lower meshes of pinion. And the mesh phase difference affects the load sharing behaviours of the two face gears. It is necessary to study the influences of the support stiffness of pinion, backlash, and tooth number design of the spur gear on the load sharing behaviours of the concentric torque-split face gear transmission.

4.1. The Support Stiffness. Due to the restriction of the designed power capacity and the space of the test gearbox that developed for the helicopter, the designed support stiffness of pinion is $2.5 \mathrm{e} 8 \mathrm{~N} / \mathrm{m}$. Multiplied by the scaling factors of $[0.1,10]$, the influence of the support stiffness of pinion on the load sharing behaviours of the upper and lower face gears is studied through numerical simulations.

The numerical simulation results are shown in Figure 15. The load distribution of the upper and lower mesh of pinion under the factor of 0.1 is $52 \%$ and $48 \%$, respectively. Between the scaling factors of 0.1 and 2 , the load distribution difference raises dramatically from $4 \%$ to $40 \%$. It is apparent that the smaller support stiffness of pinion, the better load sharing performance of the two face gears.

4.2. The Backlash. The backlash is another important load sharing design parameter that affects the load sharing of the two face gears and the two idlers. In this section, the influence of the backlash of the lower meshes of idlers and the backlash of the upper and lower meshes of pinion on the load sharing behaviours of the concentric torque-split face gear transmission is studied. 


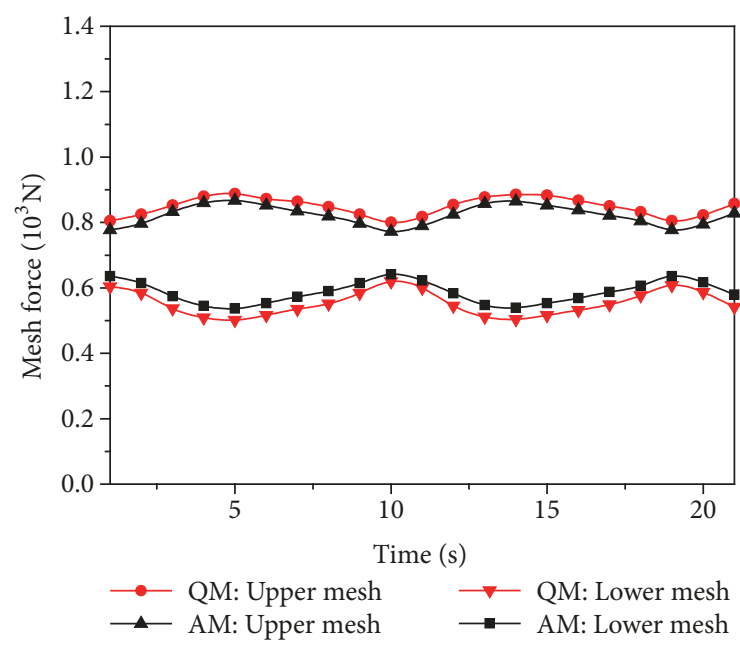

(a)

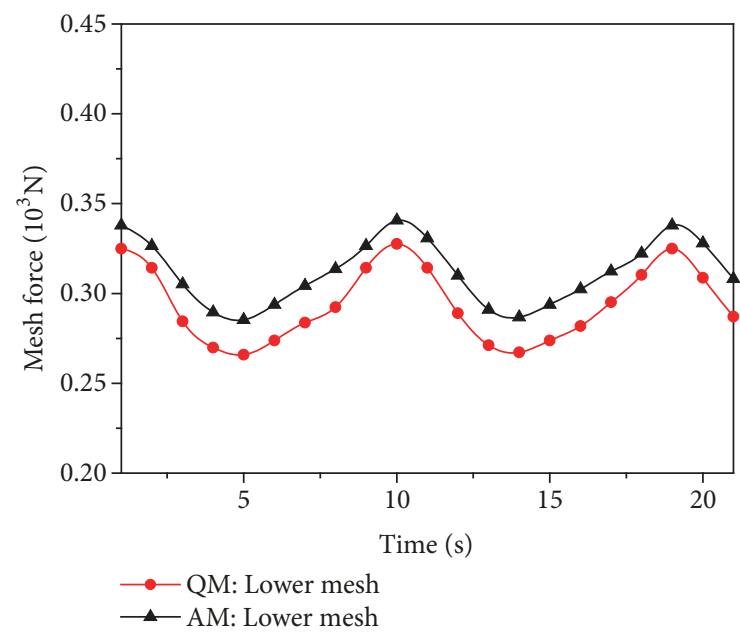

(c)

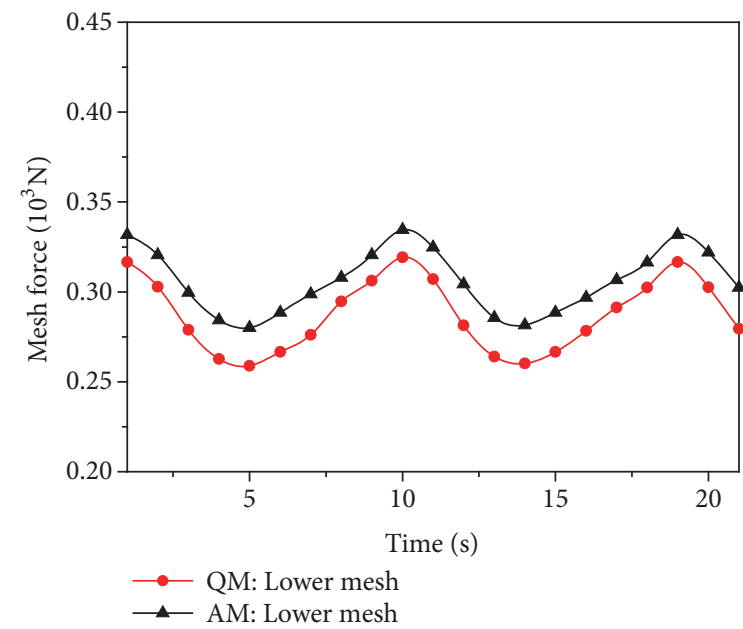

(b)

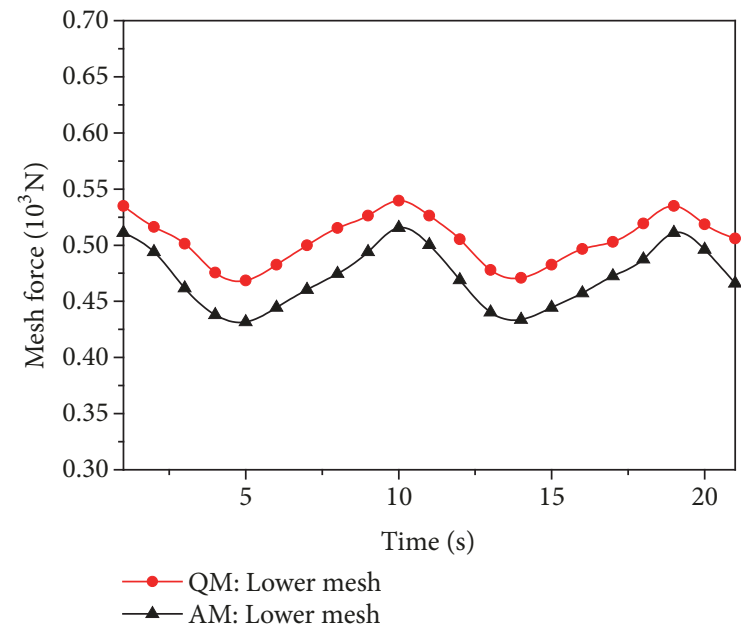

(d)

FIGURE 14: Mesh force calculated by QM and AM: (a) input pinion; (b) idler 3; (c) idler 4; (d) tail rotor.

4.2.1. The Lower Meshes of Idlers. The maximum backlash difference of the lower meshes of the two idlers is $25 \mu \mathrm{m}$. The backlash difference is multiplied by the scaling factors of $[0.1,1]$. The influence of the backlash on the load sharing behaviours between the two idlers is shown in Figure 16. By enlarging the backlash of the lower mesh of idler 3, the load split to idler 3 declines, and the load split to idler 4 raises. Under the backlash difference of $2.7 \mu \mathrm{m}$, idlers 3 and 4 got an even load sharing.

4.2.2. The Upper/Lower Meshes of Pinion. The backlash difference of the upper and lower meshes of pinion is $25 \mu \mathrm{m}$. The backlash difference is multiplied by the scaling factors of $[0.1,1]$. The influence of the backlash on the load sharing behaviours of the two face gears are shown in Figure 17. Under the designed support stiffness of pinion, the load split to the upper mesh of pinion is larger than the lower mesh. Under the largest backlash difference of $25 \mu \mathrm{m}$, the load sharing of the upper and lower meshes of pinion get $16 \%$ closer. This load sharing design method can be combined with the support stiffness of pinion to obtain a better load sharing performance of the two face gears.

4.3. The Tooth Number Design. The parity of the tooth number of the spur gears results in a mesh phase difference between the upper and lower meshes of pinion. The odd tooth number induces a half mesh phase difference between the upper and lower meshes of pinion, while the even tooth number induces none mesh phase difference between the upper and lower meshes. In this section, the influence of the parity of the tooth number on the load sharing behaviours of the upper and lower face gears are studied.

The numerical simulation results are shown in Figure 18. The load sharing behaviours of the two face gears are studied in a whole mesh circle under the condition of odd and even tooth number design of the spur gears.

The maximum load sharing coefficient of the odd tooth number design is 1.82 . While the corresponding result of the even tooth number design is 1.77 . It can be concluded 


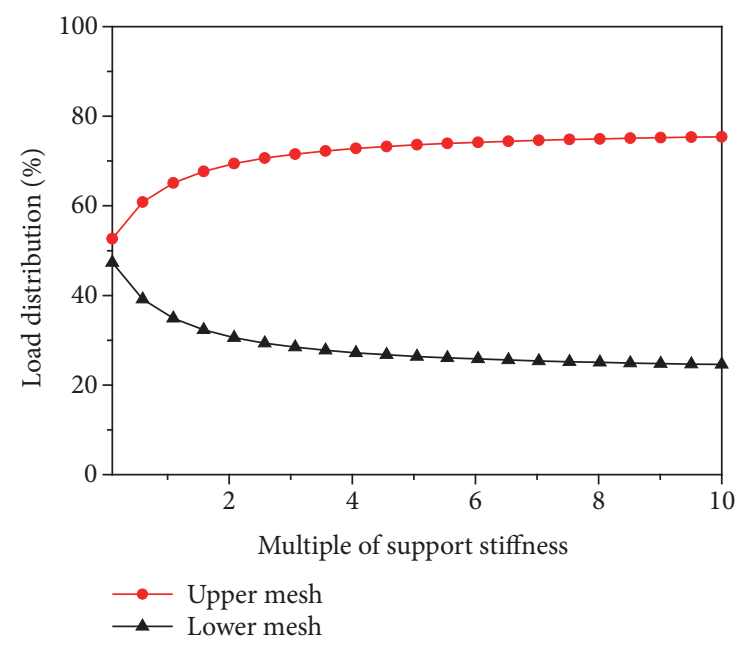

FIGURE 15: The influence of support stiffness on the load sharing behaviours of the two face gears.

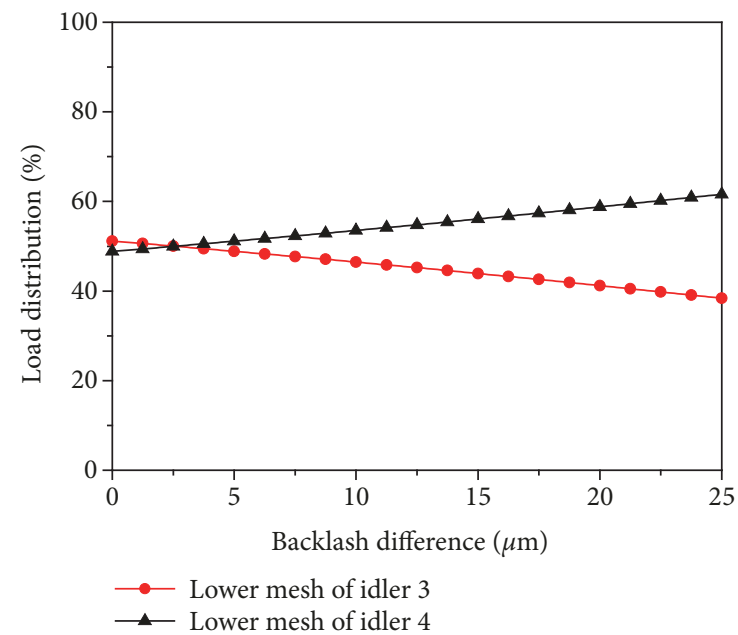

FIGURE 16: : The influence of the backlash on the load sharing behaviours of the two idlers.

that the even tooth number design has a better load sharing performance than the odd tooth number design.

\section{Conclusions}

In this paper, a quasistatic load sharing analytical model of the concentric torque-split face gear transmission with flexible face gear body is established. The proposed model is a hybrid of lumped parameter and 3D finite element. The connection between the spur gears and 3D finite element nodes of the face gear are established. From a practical viewpoint, this model makes it possible for a quick and precision load sharing behaviour analysis in contrast to the commercial software ANSYS. A number of numerical simulations are presented. These load sharing analysis results provide guidance for the load sharing design of the concentric torque-split face gear transmission. Based on the numerical simulation results, the following conclusions have been reached:

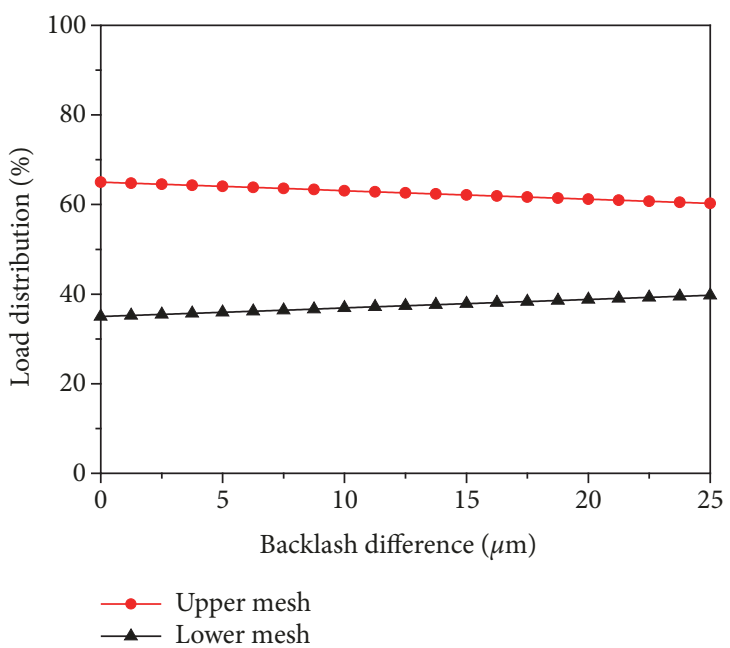

Figure 17: The influence of the backlash on the load sharing behaviours of the two face gears.

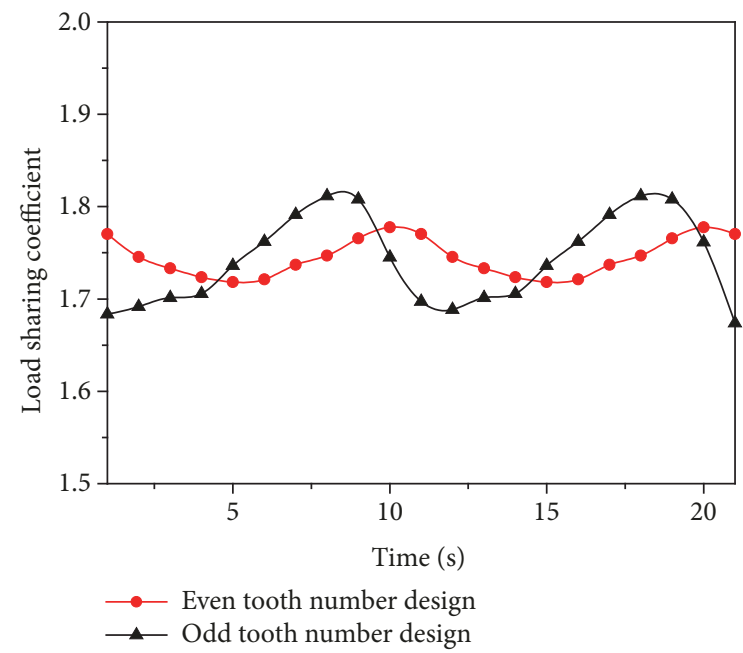

Figure 18: The influence of the parity of the tooth number of the cylindrical gear on the load sharing coefficient between the upper and lower meshes of pinion.

(a) The support stiffness of pinion has significant influence on the load sharing behaviours of the two face gears. Smaller support stiffness should be selected under allowable condition.

(b) The backlash is a key design parameter for the load sharing of the two face gears and the two idlers. The uneven load sharing of the two idlers can be eliminated by changing their backlash difference. And this backlash based load sharing design method should be combined with the support stiffness of pinion to achieve an even load sharing of the two face gears.

(c) Even tooth number design of the spur gear has a better load sharing performance of the two face gears than the odd tooth number design. 


\section{Data Availability}

The data used to support the findings of this study are available from the corresponding author upon request.

\section{Disclosure}

This manuscript has been presented in the Proceedings "International Gear Conference 27th-29th August 2018" since the paper was published as a proceeding in the conference: https://int-gear-conf18.sciencesconf.org/data/pages/Programme_GEAR2018_V3.pdf.

\section{Conflicts of Interest}

The authors declare that there are no conflicts of interest regarding the publication of this paper.

\section{Acknowledgments}

The authors gratefully acknowledge the support of the National Natural Science Foundation of China (Grant no. 51675424).

\section{References}

[1] G. Andrei, Face gear transmission, in particular for aircraft application, EP 0995929 A3[P], CA, 2000.

[2] G. Andrei, Face gear transmission assembly, in particular for aircraft application, US 6260429 B1[P], US, 2001.

[3] P. Nett H, Power-split angular gear, US6889572[P], US, 2005.

[4] R. Pias and S. Turro, Face-gear transmission assembly with floating balance pinions, EP, US5974911[P], 1999.

[5] Y. Z. Gmirya and J. G. Kish, Split-torque face gear transmission, US 6612195 B2[P], US, 2003.

[6] F. L. Litvin, A. Fuentes, J. M. Hawkins, and R. F. Handschuh, Handschuh, Design, generation and tooth contact analysis (TCA) of asymmetric face gear drive with modified geometry, NASA TM-2001-210614 ARL-TR-2373, 2001.

[7] F. L. Litvin, A. Fuentes, C. Zanzi, and M. Pontiggia, "Design, generation, and stress analysis of two versions of geometry of face-gear drives," Mechanism and Machine Theory, vol. 37, no. 10, pp. 1179-1211, 2002.

[8] F. L. Litvin, A. Fuentes, C. Zanzi, M. Pontiggia, and R. F. Handschuh, "Face-gear drive with spur involute pinion: Geometry, generation by a worm, stress analysis," Computer Methods Applied Mechanics and Engineering, vol. 191, no. 25-26, pp. 27852813, 2002.

[9] F. L. Litvin, A. Nava, Q. Fan, and A. Fuentes, "New geometry of face worm gear drives with conical and cylindrical worms: Generation, simulation of meshing, and stress analysis," Computer Methods Applied Mechanics and Engineering, vol. 191, no. 27-28, pp. 3035-3054, 2002.

[10] C. Zanzi and J. I. Pedrero, "Application of modified geometry of face gear drive," Computer Methods Applied Mechanics and Engineering, vol. 194, no. 27-29, pp. 3047-3066, 2005.

[11] J. Tang Y, F. Yin, and M. Chen X, "The principle of profile modified face-gear grinding based on disk wheel," Mechanism \& Machine Theory, vol. 70, no. 6, pp. 1-15, 2013.
[12] I. Tsuji, H. Gunbara, K. Kawasaki, and A. Takami, "Machining and running test of high-performance face gear set," in Proceedings of the ASME 2011 International Design Engineering Technical Conferences and Computers and Information in Engineering Conference, IDETC/CIE 2011, pp. 73-80, USA, August 2011.

[13] S. Barone, L. Borgianni, and P. Forte, "Evaluation of the effect of misalignment and profile modification in face gear drive by a finite element meshing simulation," Journal of Mechanical Design-Transactions of the ASME, vol. 126, no. 5, pp. 916-924, 2004.

[14] M. Peng, H. A. DeSmidt, and J. Zhao, "Parametric Instability of Face-Gear Drives Meshing with Multiple Spur Pinions," Journal of Mechanical Design, vol. 137, no. 12, 2015.

[15] Z. Hu, J. Tang, S. Chen, and D. Lei, "Effect of mesh stiffness on the dynamic response of face gear transmission system," Journal of Mechanical Design, vol. 135, no. 7, Article ID 071005, 2013.

[16] M. Ajmi and P. Velex, "A model for simulating the quasi-static and dynamic behaviour of solid wide-faced spur and helical gears," Mechanism and Machine Theory, vol. 40, no. 2, pp. 173190, 2005.

[17] V. Abousleiman and P. Velex, "A hybrid 3D finite element/lumped parameter model for quasi-static and dynamic analyses of planetary/epicyclic gear sets," Mechanism and Machine Theory, vol. 41, no. 6, pp. 725-748, 2006.

[18] V. Abousleiman, P. Velex, and S. Becquerelle, "Modeling of spur And Helical Gear Planetary Drives With Flexible Ring Gears And Planet Carriers," Drive System Technique, vol. 129, no. 1, pp. 711-722, 2009.

[19] M. N. Bettaïeb, P. Velex, and M. Ajmi, "A static and dynamic model of geared transmissions by combining substructures and elastic foundations - Applications to thin-rimmed gears," Journal of Mechanical Design, vol. 129, no. 2, pp. 184-194, 2007.

[20] M. S. Abbes, M. Trigui, F. Chaari, T. Fakhfakh, and M. Haddar, "Dynamic behaviour modelling of a flexible gear system by the elastic foundation theory in presence of defects," European Journal of Mechanics - A/Solids, vol. 29, no. 5, pp. 887-896, 2010.

[21] B. Guilbert, P. Velex, D. Dureisseix, and P. Cutuli, "A MortarBased Mesh Interface for Hybrid Finite-Element/LumpedParameter Gear Dynamic Models - Applications to ThinRimmed Geared Systems," Journal of Mechanical Design, vol. 138, no. 12, Article ID 123301, 2016.

[22] R. G. Parker and X. Wu, "Vibration modes of planetary gears with unequally spaced planets and an elastic ring gear," Journal of Sound and Vibration, vol. 329, no. 11, pp. 2265-2275, 2010.

[23] X. Wu, Vibration of Planetary Gears Having an Elastic Continuum Ring Gear Dissertation [Dissertation, thesis], 2010.

[24] R. G. Parker and X. Wu, "Parametric instability of planetary gears having elastic continuum ring gears," Journal of Vibration and Acoustics, vol. 134, no. 4, Article ID 041011, 2012.

[25] F. G. Heath, R. Filler, and J. Tan, Development of Face Gear Technology for Industrial and Aerospace Power Transmission, 2002.

[26] R. Filler, F. G. Heath, C. S. Slaughter et al., "Torque splitting by a concentric face gear transmission," Filler Robert R, 2002.

[27] J. Tang, Z. Hu, S. Chen, and D. Lei, "Effects of directional rotation radius and transmission error on the dynamic characteristics of face gear transmission system," Proceedings of the Institution of Mechanical Engineers, Part C: Journal of Mechanical Engineering Science, vol. 228, no. 7, pp. 1108-1118, 2014. 


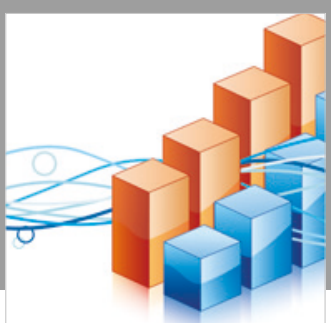

Advances in

Operations Research

\section{-n-m}
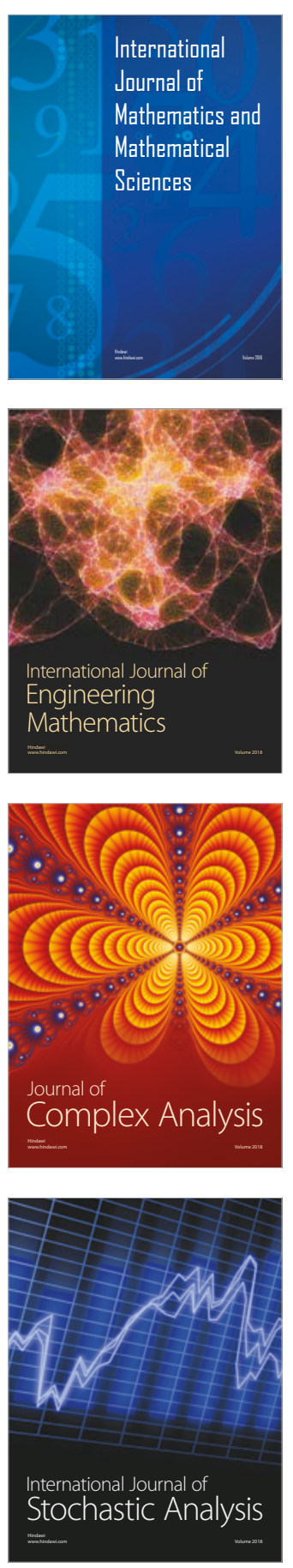
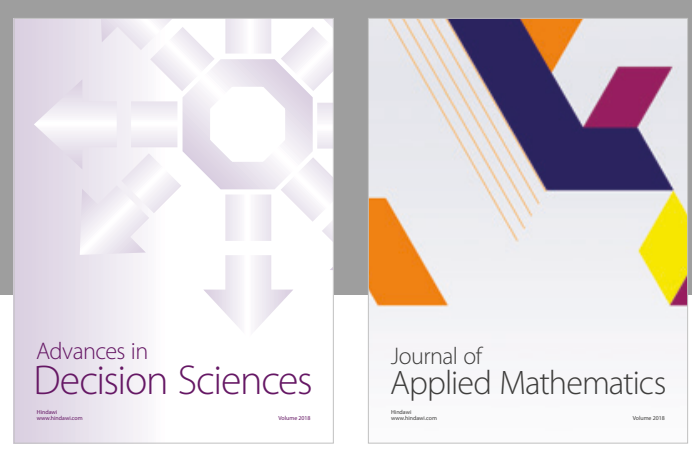

Journal of

Applied Mathematics
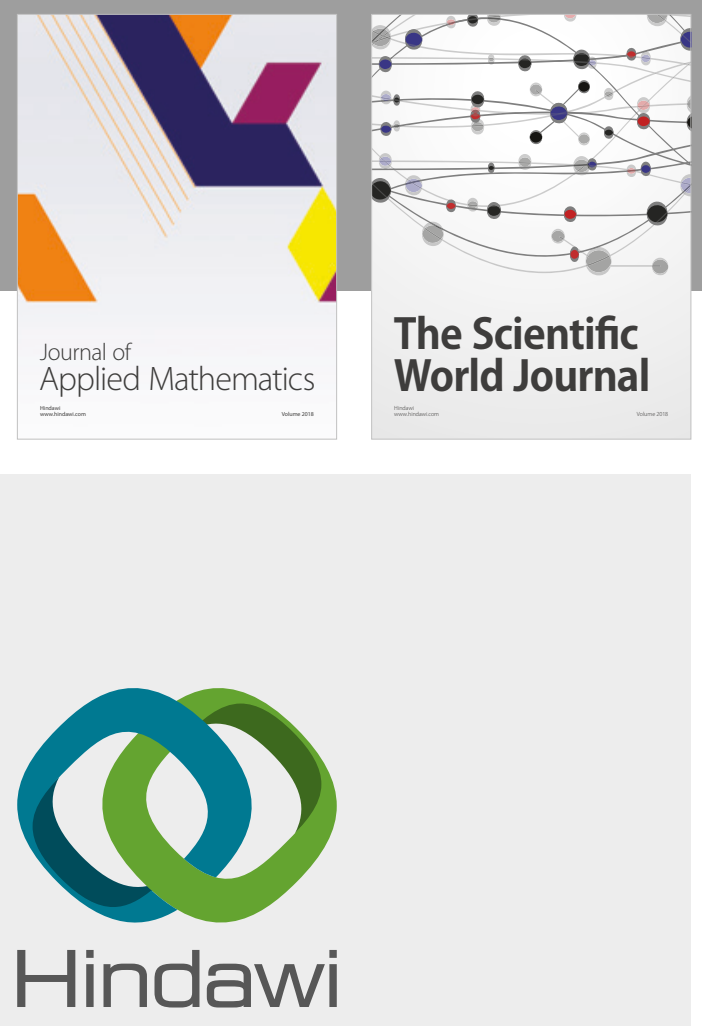

Submit your manuscripts at

www.hindawi.com

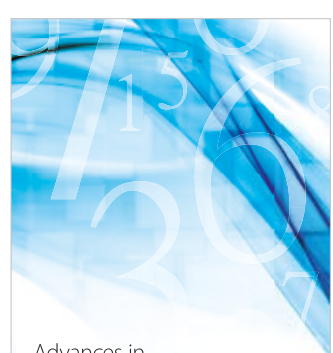

Advances in
Numerical Analysis
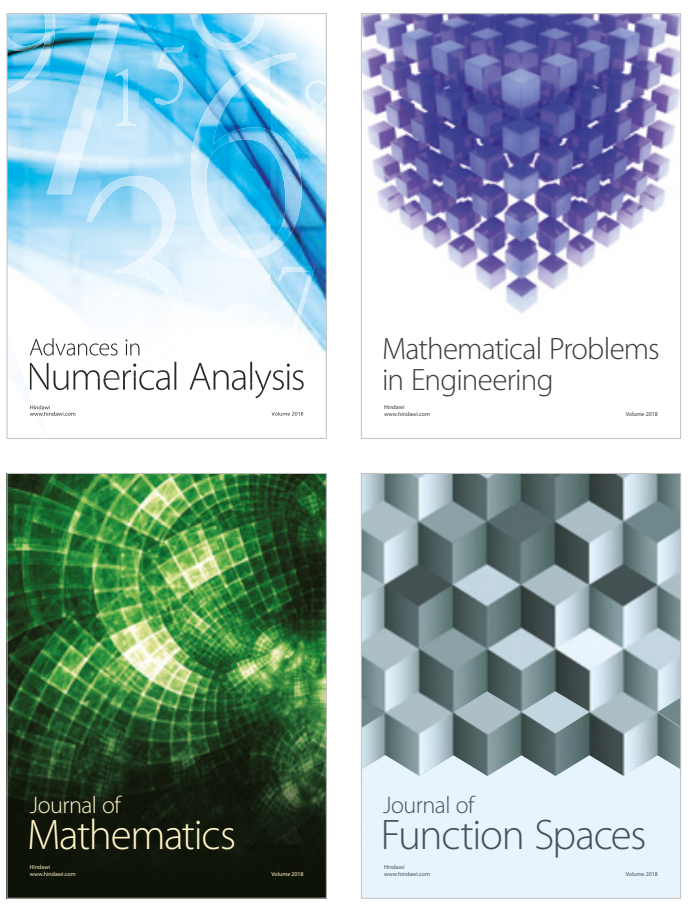

Mathematical Problems in Engineering

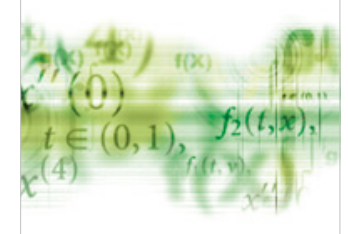

International Journal of

Differential Equations

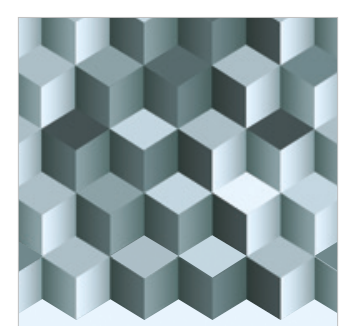

Journal of

Function Spaces

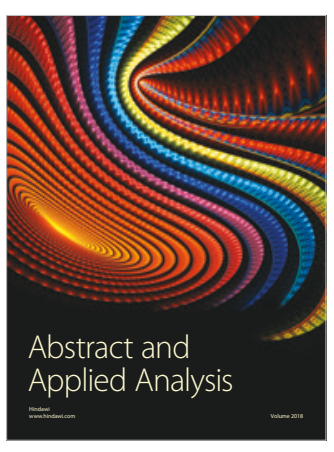

The Scientific

World Journal

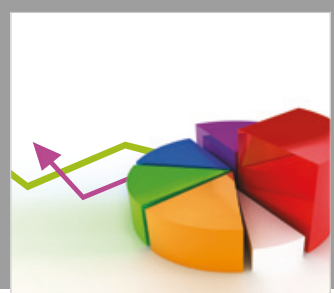

Journal of

Probability and Statistics
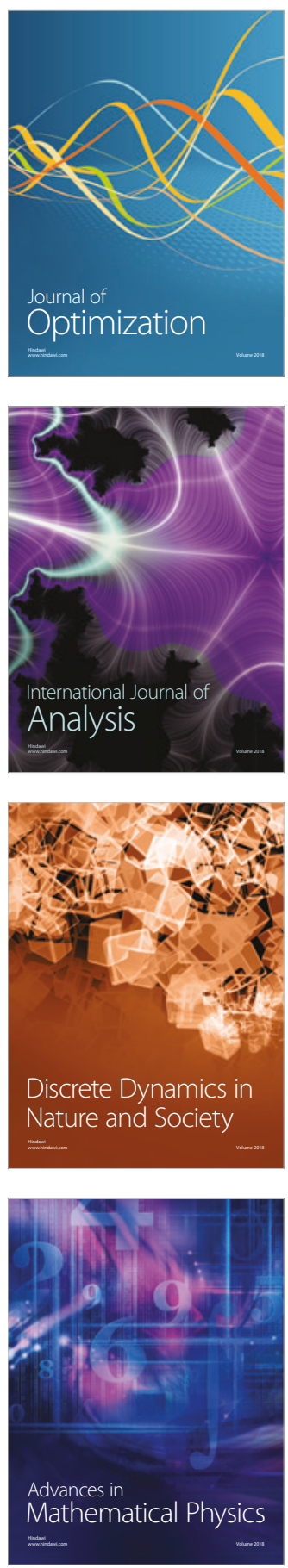